\title{
Plataformas (como Redalyc), revistas, libros y artículos digitales. ¿Cómo abrir el campo de cuestiones científicas sin quedar atrapado por una lógica comercial?
}

Platforms (such as Redalyc), journals, books and digital articles. How to open the field of scientific questions without being trapped by a commercial logic?

Jean-Claude Guédon

Université de Montréal, Canadá

Buenos días. ${ }^{1}$

Me gustaría agradecer a los organizadores de la conferencia por esta invitación. Lástima, no pude estar allí en Perú, pero estoy en espíritu con ustedes. Mi español es muy débil, si ustedes quieren pueden reírse porque entiendo que esto es muy chistoso.

Lo que me gustaría discutir con ustedes hoy es, en primer lugar, la cuestión de las plataformas de revistas: cómo emergen y cómo van a cambiar las cosas en el mundo de la publicación científica.

¿Qué son las plataformas? Redalyc, por supuesto, es una de ellas. Me parece que, en primer lugar, las plataformas trabajan como lo que podríamos llamar una "estantería", como las que encontramos en las bibliotecas. Es decir que las revistas se encuentran encima de una estantería y los lectores, de una manera muy sencilla, seleccionan la revista que quieren, y dentro de ella seleccionan el artículo que necesitan y leen eso. Esa es la función más básica de la plataforma, pero es muy fácil ver que hay muchas otras cosas que aparecen con las plataformas. De una forma muy abstracta quizás, o formalizada, podríamos decir que una plataforma organiza la sociología de los textos y la manera de releerlos. Es decir que cuando ustedes manejan libros sobre una estantería, están organizando la posibilidad de encontrar libros que el lector no conoce, ya que a través de este sistema de organización los libros se encuentran cerca de nosotros, y esta es una manera de descubrir textos desconocidos. Este es el tipo de función que en una plataforma trabaja muy bien, y es importante mantenerla como una función básica para el desarrollo de las plataformas.

$\mathrm{Al}$ mismo tiempo, la manera de leer un texto con una plataforma es una manera que está muy organizada por el aparato que se llama computadora. Y por eso es muy importante mantener eso, también, en la organización de una plataforma. No leemos un texto digitalizado de la misma manera que un texto que fue impreso.

Últimamente, una plataforma ha cambiado la significación de lo que es una revista y de lo que es un artículo. Es decir, la plataforma puede reorganizar artículos de distintas maneras para presentarlos con títulos diferentes que podrían reflejar una revista movil, una revista que puede cambiar con el tiempo, una revista que puede vivir durante algunos años alrededor de un tema o un problema y después desaparecer sin que desaparezcan los artículos y sin que desaparezcan las formas originales de la plataforma y de las revistas. Y por eso me parece que es importante organizar la plataforma para ofrecer puntos de vista y enfoques diferentes tal como se desarrollan a lo largo del tiempo cuando los investigadores evolucionan o cambian sus perspectivas de investigación o sus perspectivas teóricas. Esta es otra función muy importante de las plataformas.

La otra cosa que es muy importante es que una plataforma a menudo se ve como una cosa sencilla y aislada de las otras plataformas. A mí me parece un error considerar una plataforma como una entidad particular, sin vinculaciones con otras plataformas. Me parece que la cuestión del vínculo entre las plataformas debe ser cuidadosa, para, esencialmente, mantener vínculos con plataformas que sean compatibles con ella. Y al mismo tiempo, se debe pensar que la plataforma no vive como un sistema aislado, y que no va a perder su identidad si se vincula con otras plataformas. La ventaja de esto es que se produce un efecto de red que puede 
amplificar la acción y el efecto de la plataforma; se puede organizar para el resto del mundo un sistema mucho más poderoso a través de este tipo de vinculación, de networking, de red. Y al mismo tiempo, dentro de la red, cada plataforma, en sus órganos - como los artículos en las revistas-, puede mantener una identidad muy clara, identificar esas entidades con la plataforma, o con un proyecto particular o cualquier cosa.

Me parece que la vinculación de plataformas es muy importante y esto puede hacerse de varias maneras. Por ejemplo, una plataforma podría sencillamente atraer la atención de los lectores hacia otras plataformas e intercambiar la visibilidad con ellas. Si, por ejemplo, plataformas como SciELO o Redalyc, Revues.org en Francia, Érudit en Canadá u otras plataformas de revistas pudieran organizar un vínculo entre ellas, cada una de ellas podría ver su trabajo amplificado por la vinculación.

Las plataformas no están únicamente compuestas por revistas; puede tratarse también de una plataforma que vincule muchos repositorios, y por eso hay posibilidades también de organizar una amplificación de su visibilidad con vínculos con, por ejemplo, OpenAIRE en Europa, La Referencia en América del Sur u otros grupos de repositorios que por su lado están desarrollando funciones que siempre se acercan más a lo que podemos llamar una publicación. Y por eso me parece interesante explorar la posibilidad de vincular los repositorios y sus plataformas con plataformas de revistas. Próximamente, repositorios de articulos y revistas en plataformas van a vivir juntos, como una sola entidad porque hay una dinámica de convergencia entre las revistas y los repositorios.

El objetivo de una plataforma no está en la proyección, la diseminación, ya que con el Acceso Abierto todo está ofrecido al mundo. Lo más importante es hacer de las plataformas un escenario de visibilidad y de prestigio para investigadores en muchas partes del mundo. Es decir, si una plataforma como Redalyc pudiera ofrecer a los investigadores de todos los países la posibilidad de ser publicados en lenguas que no sean únicamente el español o el portugués (e incluso el inglés), les permitiría también ser publicados de una manera más eficaz. Para amplificar esa función, sería muy importante que en el momento de evaluar, los organismos que financian la investigación en todas partes del mundo pudieran declarar de una manera muy obvia que cualquier artículo publicado por la plataforma Redalyc tiene tanto valor como uno publicado por otra plataforma (incluyendo plataformas comerciales), y que la única cosa que es importante no es la plataforma en sí misma sino la calidad de los artículos. Y así podríamos decir que plataformas como Redalyc, como SciELO, como Revues.org, presentan publicaciones que tienen un nivel de calidad semejante al de las plataformas bien conocidas en el mundo, por ejemplo algunas plataformas comerciales.

De este modo, muchos investigadores que no pueden comprar el derecho de ser publicados por una plataforma comercial (que cuesta mucho) podrían mandar sus artículos a Redalyc y saber que son tratados de una manera correcta y sin problemas frente a los organismos de financiamiento de la investigación, y quizás también a los comités de evaluación de las promociones de los investigadores dentro de las universidades o centros de investigación.

Es decir que la promoción de una plataforma no se incorpora en un sistema como el de una revista comercial, que quiere ser vendida en muchas bibliotecas. Es más: el objetivo de organizar una visibilidad creíble junto con todos los sitios de evaluación de investigadores, y el contacto directo entre la plataforma (o quizás una red de plataformas, que es más poderosa) y los grandes organismos de financiamiento de la investigación en el Norte, podría tener consecuencias mucho más importantes que, por ejemplo... ¡ cómo se dice?..., la publicidad de la plataforma o cualquier otra manera de difundir y diseminar el conocimiento sobre la misma. Esta me parece una estrategia que no fue explorada y que podría ayudar muchísimo a completar el primer paso, que es organizar redes de plataformas que tienen un objetivo común.

En segundo lugar, me gustaría discutir un poco sobre las revistas. Hay un fetichismo respecto de las revistas, y eso necesita ser analizado.

Las revistas solían ser la voz de las comunidades de científicos, de investigadores, en el siglo XIX, y en el siglo XX hasta la Segunda Guerra Mundial. Es decir que grupos de investigadores organizaban sociedades científicas que solían producir revistas y esas revistas eran sostenidas con el dinero que los mismos científicos 
pagaban a la sociedad para ser miembros; era un tipo de servicio, de función, que la asociación solía cumplir. Después de la Segunda Guerra Mundial, en particular con [Eugene] Garfield y el Journal Citation Index,y después con Robert Maxwell y su Pergamon Press,la edición de revistas cambió de una manera radical; y lo que surgió, lo sabemos bien, fue un sistema en el que la revista no sirve tanto para apoyar la difusión de nuevos descubrimientos o cosas descubiertas, sino para hacer, crear, un sistema de prestigio: un sistema que fue organizado a través del Factor de Impacto. Todo eso es una locura total, pero lo cierto es que desde ese momento la naturaleza de las revistas cambió muchísimo.

La consecuencia de esa transformación de las revistas fue que se organizó un tipo de evaluación de la investigación que no se corresponde para nada con los objetivos de todos los actores de la investigación científica, con la excepción de las grandes casas de publicación. Por ejemplo CONICYT, CONACYT o CONICET, o cualquier consejo de investigación en América Latina, tienen un programa de investigación que corresponde a un tipo de política científica y sistemas de evaluación de los proyectos de los investigadores acordes a esa política. Pero una vez que se realiza la selección del grupo que va a hacer o tomar en cuenta un programa de investigación, las implicaciones que salen de ese grupo llevan a tomar la evaluación de maneras diferentes. Lo que es importante para una revista que funciona con el Factor de Impacto es: "me pregunto si el artículo que el grupo me mandó va a ayudar a la posibilidad de tener más citaciones y de esa manera va a ayudar al crecimiento de mi Factor de Impacto". Y todo eso tiene consecuencias en la selección de temas de investigación que son, podríamos decir, hot problems o in fashion, u otras cosas así. El resultado es que problemas muy originales, así como problemas importantes que no interesan al Norte o no interesan a las revistas, no pueden ser estudiados; y que toda la gente se precipita en la misma dirección, que en un momento dado son los temas "importantes" de la investigación científica. Este proceso explica muchísimo la razón por la cual hay muchos problemas importantes que no son estudiados. Necesitamos decenas de años para ver algunos estudios sobre ébola o zika, y esto se explica por ese tipo de política implícita de las revistas de prestigio internacional (o como quieran llamarlas), que de una manera muy fuerte pero no muy visible, orientan la investigación científica en direcciones específicas, desconociendo la posibilidad de responder a los problemas asociados con regiones o países particulares del mundo. Eso significa también que la base de la ciencia se vuelve más estrecha ¿Cómo sería si la ciencia fuera organizada de manera diferente?

En una plataforma, como lo dije, las revistas pueden ser creadas sobre la base de artículos que estén disponibles inmediatamente a través de otras revistas. Por ejemplo, si tenemos una emergencia sobre el virus del ébola sería muy fácil y muy rápido ordenar un grupo de artículos en Acceso Abierto sobre este tema, que permitiera a la comunidad científica organizarse con eficacia para estudiar este problema. Al mismo tiempo, esto ofrecería visibilidad a revistas que giran en torno a problemas específicos (y no únicamente con respecto a la disciplina, a sitios importantes en donde éstas se desarrollan o a los intereses económicos de compañías comerciales).

Me parece que en una plataforma como Redalyc la gente podría seguir problemas importantes, por ejemplo, de América del Sur y del Norte (de México); y quizás podrían hacerse selecciones de artículos que en esta plataforma están diseminados en muchas revistas, y organizarlas en grupos muy coherentes para impulsar otras investigaciones sobre este tema. Me parece una estrategia que podría ofrecer resultados interesantes para la investigación científica y que corresponde muy bien al valor de lo que es una plataforma.

En una plataforma, de todas maneras, la importancia de las revistas disminuye. Esto se ve de una manera muy clara en las grandes plataformas comerciales. Cuando ustedes utilizan ScienceDirect, por ejemplo, van a buscar un artículo en una revista particular, pero la plataforma los orienta hacia otros artículos que vienen de otras revistas, y por esto la noción de vinculación entre artículos es más importante que la relación de artículos existentes dentro de una revista. Es toda la plataforma la que ofrece un paisaje intelectual al investigador, y no sólo y únicamente una revista. Me parece que es una noción que hay que mantener porque permite hacer una sociología de los textos, y crear nuevas "revistas" que la plataforma puede organizar. Este es otro punto 
que me parece importante y por el cual revistas con plataformas van a cambiar de una manera radical, me parece, en los próximos diez años.

Además, quiero referirme a los artículos, que también van a cambiar. Me parece que la noción de artículo va a transformarse porque es una noción que viene de la imprenta. Realmente viene de la imprenta: el artículo es la transposición de la carta que los científicos en los siglos XVI y XVII solían mandar a los otros a través de un sistema postal que empezaba a desarrollarse en Europa en ese tiempo. En este momento no estamos en una situación de hablar o pensar en la imprenta, pero con el artículo somos... ¿ cómo se dice?... prisioners[prisioneros] de la imprenta. El artículo es una cosa un poco loca. El artículo obliga a ejecutar todas las funciones de la publicación al mismo tiempo: es necesario registrar a los autores, certificar el artículo, preservarlo y diseminarlo; todo en un mismo momento. Es mucho más fácil ahora ver esto en los grupos de científicos que tienen una reputación fuerte, que tienen un financiamiento a través de un organismo de financiamiento global de investigación, y por eso pueden mostrar que están en serio en la investigación.

Es muy sencillo imaginar la posibilidad de, en primer lugar, ofrecer el acceso al artículo antes de la evaluación por pares; antes de todo. Es decir, la plataforma recibe un artículo y lo muestra en una sección muy visible para ofrecerlo a la comunidad que se interesa en este tipo de problemas, y así sus miembros pueden ver cuáles son los últimos trabajos en ese campo. Es decir que la accesibilidad al artículo puede darse meses (o quizás, en algunos casos, años) antes de lo que lo permite el proceso actual. Después, una vista de la revisión por los pares puede hacerse de una manera pública, de una manera abierta, y los comentarios pueden ayudar a enriquecer el archivo científico ya que habría cosas importantes que son dichas en sus comentarios. Además, ese tipo de proceso permitiría que los autores puedan cambiar: más autores podrían colaborar y algunos podrían decidir no mantenerse; y los autores definitivos podrían ofrecer acceso a una segunda versión del artículo que tuviera en cuenta los comentarios o las sugerencias de los pares.

El modelo que estoy proponiendo no es mío: es el modelo de una pequeña empresa en el Reino Unido que se llama F1000Research (F1000Investigación). Es una invención, principalmente, de Vitek Tracz, que es bien conocido en el Acceso Abierto porque es quien inventó también el APC -article processing charges-,que no fue un invento tan bueno desde mi punto de vista (pero ese es otro problema...). La perspectiva que ofrece F1000Research es muy interesante porque el artículo se modifica en un flujo de conversaciones que son el resultado del trabajo de muchos científicos sobre un problema en particular; es decir que, de una manera realmente eficaz, los investigadores se organizan para crear lo que la ciencia realmente inventa en el siglo XVII, es decir un sistema distribuido de inteligencia que es compartida por muchos investigadores.

Recomiendo a ustedes que echen una mirada al programa de F1000Research; hay muchas ideas que son muy interesantes; en particular, un artículo no puede capturar el flujo de una conversación. El modelo es realmente el modelo del software libre: no hay publicaciones en los programas de software libre, hay únicamente posibilidades de ofrecer versiones del programa; y el programa evoluciona, cambia con el tiempo. Esto modifica muchísimo la significación de lo que es un artículo. En inglés se dice, sobre los programas libres o sobre el programa de F1000Research: "Don't publish; release” [No publiques! Liberes!]. Esta es la manera de decir eso.

La última cosa que me gustaría discutir con ustedes es una cuestión alrededor de la cual ya hablé un poco antes. Es el problema de una universalidad de la ciencia que al mismo tiempo permite la generación de problemas específicos en varias comunidades, varios países, varias organizaciones de cualquier tipo. Me parece realmente chistoso -y un poco dramático- que mucho dinero sea utilizado para apoyar a grupos de científicos que presentan un programa de investigación, y que después de esto en la selección del grupo para el organismo de financiamiento de la investigación nos encontremos en una situación en donde los resultados del trabajo son evaluados por criterios que vienen de la competencia entre revistas, en particular, de revistas comerciales. Creo que para mantener la autonomía de las investigaciones científicas en todas partes del mundo y para, al mismo tiempo ampliar, amplificar, la base de la ciencia con problemas más generales y con variaciones, la posibilidad de retomar un cierto grado de control sobre la agenda de investigación en varios 
países y en varias regiones sería muy buena por el desarrollo de la ciencia en el futuro. Creo que la vinculación en red de plataformas -que podrían funcionar como puntos focales de varios tipos de problemas apoyados por varias regiones- podría, al mismo tiempo, encontrar respuestas a las necesidades reales de un país o de una región; y a su vez, propiciar un instrumento universal de valoración de esos problemas particulares. Hay muchos ejemplos de problemas que parecen muy locales y que a la larga se transforman en trazos teóricos muy generales porque la solución específica a esos problemas necesitaba utilizar determinadas herramientas teóricas. Y por esto lo que estoy proponiendo no es hacer una ciencia provincial o aislada, sino al contrario: es organizar una diversidad de cuestiones en el campo de la ciencia que puede enriquecer la ciencia en general. Me parece que Redalyc, por su historia, por su trabajo, por su estatuto y por su visibilidad puede ayudar a desarrollar esto y jugar un papel muy importante en el tipo de programa intelectual que estoy describiendo ahora.

Estas son las cosas que quería decir; espero no haber hablado demasiado. Otra vez, muchas gracias por el privilegio de hablar con ustedes. Me habría gustado estar en Perú pero no pude, no podré hacerlo. Estoy seguro de que en el futuro vamos a vernos, a encontrarnos otra vez en cualquier parte del mundo, y en particular en alguna de las regiones tan hermosas de América Latina.

Muchas gracias y hasta la vista.

\section{Notas}

1 Transcripción de la conferencia impartida en el $3^{\circ}$ Congreso Internacional de Editores Redalyc "Construyendo el modelo de publicación académica del sur global”. Trujillo, Perú, 16-18 mayo 2018. Puede verse en: https://www.yout ube.com/watch?v=6WfToVfXa9U 